\title{
Education and debate: A sense of landscape
}

Deborah Kirklin and Richard Meakin Royal Free and University College Medical School, London

"He never entered into relation with the picture as a whole-never faced, so to speak, its physiognomy. He had no sense whatever of a landscape or scene."1

Medical humanities provides one way to get a sense of the landscape in which individuals and societies experience sickness and health. In this issue's Education and debate section Ruth Richardson, an interdisciplinary historian, uses a highly topica subject to show that an appreciation of medical history can illuminate current thinking in medicine. Her paper is offered, therefore, not simply or even primarily as an historical account but rather as a complementary perspective within the multifaceted approach offered by medical humanities. An education broadened by the humanities is, of course, no guarantee that a better doctor will be produced. ${ }^{2}$ Indeed it is history that provides us with a stark reminder of this in the form of the doctors of Nazi Germany who were highly cultivated patrons of the arts, loving family men and yet still capable of committing atrocities. ${ }^{3}$ Richardson's paper does, however, illustrate the power of history to contextualise current medical practice. She argues that some elements of medical training, as currently offered in the UK, can be inherently brutalising. The result may be to leave some doctors less humane after their training than before they began. She calls for the term "necessary inhumanity" to replace the more sanitised term "clinical detachment" on the basis that it would better remind us that only as much inhumanity as is absolutely necessary is acceptable. Richardson illustrates this argument with three historical examples of medical inhumanity that have disturbing parallels in current health scandals. Firstly she describes the moral mess that ensues when doctors have financial conflicts of interest when deciding which treatments to provide. The account of Dr French should be a warning to health economists when planning their prescribing incentive plans. In the second story Richardson tells us of the early days of transplant history when healthy teeth were taken from poor children and "donated" to rich recipients. For one recipient the teeth brought with them syphilis. For the "donors", not even fully grown, facial development and nutrition were adversely affected. In the third story Richardson tells us the history of the skeleton of Charles O'Brien, displayed in the Royal College of Surgeons, despite vigorous efforts by O'Brien, prior to his death, to ensure this did not happen. The utter contempt for the dignity and autonomy of the "donors" draws obvious comparisons with current scandals. ${ }^{4}$

Questioning medical culture and traditions has always been difficult. Medical history, as Richardson shows, can allow an uncomfortable but necessary insight into persistent failings within medicine and provide a way to challenge the paradigm. Richardson's tales also feature humane doctors who fought on behalf of patients and their rights. Honouring those medical heroes may be another way to counter the medical culture that so often casts whistleblowing as the act of either a traitor or a fool. Revealing the true nature of the landscape within which medical dramas are played out does not ensure practitioners will stick to the patients' script. Nevertheless the multidisciplinary approach that is central to arts-based medical education can, at least, improve appreciation of the many perspectives and issues pertinent to health and illness. In addition it can provide fresh insight into positive and negative developments in health care delivery and give timely warnings to those prepared to heed them.

Deborah Kirklin is Lecturer in Medical Humanities and Clinical Lecturer in Communication Skills, The Medical Humanities Unit, Department of Primary Care and Population Sciences, Royal Free and University College Medical School, London. Richard Meakin is Senior Lecturer \& Director of The Medical Humanities Unit. Author for correspondence: Dr Deborah Kirklin, Lecturer in Medical Humanities, The Medical Humanities Unit, Department of Primary Care and Population Sciences, Royal Free Campus, Rowland Hill Street, London NW3 2PF. email: d.kirklin@rfhsm.ac.uk

\section{References}

1 Sacks O. The man who mistook his wife for a hat. London: Picador, 1986: 9.

2 Meakin R, Kirklin D. Medical humanities: making better doctors or just happier ones? Medical Humanities 2000;26,1:49-50. 3 Glover J. Humanity: a moral history of the twentieth history. London: Jonathan Cape 1999: 317-97.

4 Bristol Royal Infirmary Inquiry. Interim report: removal and retention of human material. Bristol: Bristol Royal Infirmary, May 2000. 